\title{
Population Pharmacokinetic Analysis of Fevipiprant in Healthy Subjects and Asthma Patients using a Tukey's g-and-h Distribution
}

\author{
Authors \\ Affiliations \\ 1 Biostatistics \& Pharmacometrics, Novartis Institutes for \\ Biomedical Research, Cambridge, MA, USA \\ 2 Biostatistics \& Pharmacometrics, Novartis Pharma AG, \\ Basel, Switzerland \\ 3 PK Science, Novartis Pharmaceutics Corporation, East \\ Hanover, NJ, USA \\ 4 PK Science, Novartis Institutes for Biomedical Research, \\ Hyderabad, India \\ 5 PK Science, Novartis Institutes for Biomedical Research, \\ Cambridge, MA, USA
}

Xinting Wang1ㅁ, Christian Bartels², Swarupa Kulkarni ${ }^{3}$, Ramachandra Sangana ${ }^{4}$, Monish Jain ${ }^{5}$, Julia Zack ${ }^{3}$, Jing Yu

Key words

pharmacokinetics, anti-asthma / COPD drugs, clinical trials

received 12.10 .2020

accepted 29.01.2021

published online $\quad 05.03 .2021$

Bibliography

Drug Res 2021; 71: 326-334

DOI 10.1055/a-1381-6579

ISSN 2194-9379

(c) 2021. Thieme. All rights reserved.

Georg Thieme Verlag KG, Rüdigerstraße 14,

70469 Stuttgart, Germany

Correspondence

Xinting Wang, PhD

Biostatistics \& Pharmacometrics, Novartis Institutes for

Biomedical Research

250 Mass Ave,

Cambridge

$02139 \mathrm{MA}$

USA

Tel: + 16178718000

xinting.wang@novartis.com
Supplementary material is available under
http://doi.org/10.1055/a-1381-6579

ABSTRACT

Aim The objective of this analysis was to characterize the population pharmacokinetics (PK) of fevipiprant in asthma patients and to evaluate the effect of baseline covariates on the PK of fevipiprant.

Methods PK data from 1281 healthy subjects or asthma patients were available after single or once daily dosing of fevipiprant. Population PK analysis was conducted to describe fevipiprant plasma concentration data using a non-linear mixed effect modeling approach.

Results Fevipiprant PK was described by a two-compartment model with first-order absorption and first-order elimination. Exploration of fevipiprant PK in the population from the phase III studies revealed an over-dispersed and skewed distribution. This unusual distribution was described using Tukey's g-and-h distribution ( $\mathrm{TGH}$ ) on the between-subject variability of apparent clearance $(\mathrm{CL} / \mathrm{F})$. The model identified a significant impact of disease status on $\mathrm{CL} / \mathrm{F}$, with the value in healthy subjects being $62 \%$ higher than that in asthma patients. Bodyweight, age and renal function showed statistically significant impact on fevipiprant clearance; however, compared with a typical asthma patient, the simulated difference in steady-state exposure was at most $16 \%$.

Conclusion Fevipiprant PK was described by a two-compartment model with first-order absorption and first-order elimination. The TGH distribution was appropriate to describe the over-dispersed and skewed PK data as observed in the current studies. Asthma patients had approximately $37 \%$ higher exposure than healthy subjects did. Other covariates changed exposure by at most $16 \%$.

\section{Introduction}

Asthma is a heterogeneous inflammatory disease that is characterized by a range of different phenotypes [1]. In recent years, accumulating evidence is showing that prostaglandin D2 (PGD2) plays an important role in the inflammatory process and pathophysiology in asthma [2]. Through its interaction with PGD2 receptor 2
(DP2, also known as CRTH2), PGD2 is involved in the migration and activation of inflammatory cells in asthma, including eosinophils, basophils, Th2 cells, as well as type 2 innate lymphoid (ILC-2) cells [3]. The recruitment of these cells into the lung is partially responsible for the intermittent airway obstruction, which leads to the wheezing and shortness of breath characteristic of asthma $[4,5]$. 
Fevipiprant, also known as QAW039, is a selective, competitive and reversible antagonist of the human DP2 receptor [6]. By binding to DP2 receptors on the inflammatory cells, fevipiprant is expected to inhibit migration and activation of these cells into the airway tissues, blocking the PGD2-driven release of Th2 cytokines, and subsequently provide treatment benefits in asthma patients [7]. Previous clinical evidence showed the treatment potential of fevipiprant in reducing sputum eosinophil count and improving the lung function in asthma patients [8,9].

Luster 1 (CQAW039A2307, abbreviated as A2307, clinicaltrials. org: NCT02555683) and Luster 2 (CQAW039A2314, abbreviated as A2314, clinicaltrials.org: NCT02563067) were two Phase III studies investigating the efficacy and safety of fevipiprant in asthma patients who are on medium or high dose of inhaled corticosteroids plus 1 or 2 additional controllers [10,11]. Sparse pharmacokinetic (PK) samples were collected in these studies to characterize the exposure of fevipiprant in this patient population.

The purpose of this analysis is to characterize the population PK of fevipiprant in the patient population from the studies A2307 and A2314. Factors that might affect the PK of fevipiprant in this population were explored.

Population PK parameters are often modeled on a lognormal scale, assuming a lognormal distribution of PK data [12]. However, log-transformation of the population PK parameters might not be sufficient, if the data is over-dispersed and/or skewed. Tukey's gand-h (TGH) distribution, which includes skewness and tail-heaviness parameters, could be more advantageous to capture such a non-normal distribution [13]. The present population PK analysis uses the TGH distribution to describe the over-dispersed and skewed PK data observed in fevipiprant Phase III studies.

\section{Methods}

\section{Study design}

The Phase III studies were multi-center, randomized, double-blind, placebo-controlled studies in asthma patients with a daily fevipiprant dose of $150 \mathrm{mg}, 450 \mathrm{mg}$ or matching placebo for 52 weeks [10]. PK data were available on 4 different visits in the 52 -week follow-up period. Two PK samples were collected on each visit, including a pre-dose ( $\mathrm{Cmin}$ ) and a 2-hour post-dose (Cmax) sample.

To support the population PK modeling and stabilize the model parameters, PK data from 7 Phase I studies in healthy subjects were also included, in which rich PK sampling was available. Among the included Phase I studies, there were 2 drug-drug-interaction (DDI) studies and 1 bioequivalence study. To focus the analysis on relevant data, cohorts in the DDI studies were excluded where fevipiprant was dosed together with an interacting drug. Additionally, one cohort in the bioequivalence study was excluded from the analysis, since the drug batch in this cohort was not used in either of the Phase III studies.

Further details of the studies are given in $>$ Table 1 . All studies were approved by corresponding ethics committee or independent review board, and conducted according to the ethical principles of Declaration of Helsinki and Good Clinical Practice. Written informed consent was obtained from all individual participants prior to study enrolment.

\section{Analysis of plasma fevipiprant}

Fevipiprant in plasma from all studies was analyzed by a validated liquid chromatography equipped with tandem mass spectrometry (LC-MS/MS). The lower limit of quantification is $1 \mathrm{ng} / \mathrm{mL}$.

\section{Missing data and samples below the lower limit of quantification (BLOQ)}

Out of the 1281 subjects included in the PK analysis, 1 subject was reported to have missing weight, 3 subjects with missing estimated glomerular filtration rate (eGFR) and 4 subjects with missing absolute glomerular filtration rate (GFR). The missing covariates were imputed by the population median values of the corresponding study. There was no missing categorical covariate.

Approximately $5 \%$ of the post-dose PK samples were BLOQ. These samples were included in the analysis by M3 censoring [14].

\section{Data analysis and modeling methods}

Model development and analysis were implemented in NONMEM 7.3 (ICON, Ellicott City, MD) [15]. Perl-speaks-NONMEM (PsN) 4.6.0 was used to facilitate NONMEM processing [16]. The statistical package R 3.4.3 was used for post-processing of NONMEM outputs [17]. All NONMEM model analysis was performed using a chain of expectation-maximization methods consisting of Iterative Two Stage (ITS) method, Stochastic Approximation Expectation Maximization (SAEM) method and Monte Carlo Importance Sampling (IMP). Goodness-of-fit plots were used to guide model development.

Based on previous knowledge of fevipiprant PK, model development was initiated with a 2-compartment model with first-order absorption, and parameterized using absorption rate constant (Ka), apparent clearance $(\mathrm{CL} / F)$, apparent central volume of distribution $(\mathrm{Vc} / F)$, apparent inter-compartmental clearance $(\mathrm{Q} / \mathrm{F})$ and apparent peripheral volume of distribution ( $\mathrm{Vp} / \mathrm{F})$. Between-subject variability (BSV) was tested on all structural parameters assuming a lognormal distribution. In case a parameter showed skewed and/ or over-dispersed distribution, the TGH distribution was evaluated to describe the BSV as below [13]:

$$
\begin{aligned}
& \eta_{i}=\frac{e^{g \cdot Z_{i}}-1}{g} \cdot e^{\left(h \cdot Z_{i}^{2} / 2\right)} \cdot s, Z_{i} \sim N(0,1) \\
& \theta_{i}=\theta \cdot e^{\eta_{i}}
\end{aligned}
$$

Here, $\eta_{i}$ represents the BSV of parameter $\theta . g$ controls skewness, $h$ tail-heaviness and $s$ the scale, respectively. $Z_{i}$ follows a standard normal distribution. The value of parameter $\theta$ in subject $i\left(\theta_{i}\right)$ is a multiplication of the typical population value $(\theta)$ and the BSV $\left(\eta_{i}\right)$.

BSV was included on all structural parameters using MU reference to improve model stability and efficiency [15]. Given the relatively sparse samples in Phase III studies, not all BSVs could be estimated and, in such cases, they were fixed with a variance equal to 0.0081 (CV\%: $9 \%$ ). The value of $9 \%$ CV was chosen as a compromise between the values given in examples from Bauer RJ and Bonate $P$., which ensures an efficient estimation of the population mean parameters with similar individual parameter values in each subject $[15,18]$.

A combination of additive and proportional error was tested in the model. 
- Table 1 Summary of included studies

\begin{tabular}{|c|c|c|c|c|}
\hline Study & Design & Dose and regimen & Patient population & PK sampling times \\
\hline A2307 & $\begin{array}{l}\text { Phase III, efficacy, } \\
\text { safety }\end{array}$ & $\begin{array}{l}150 \text { and } 450 \mathrm{mg} \text { QD } \\
\text { for } 52 \text { weeks. }\end{array}$ & Asthma patients & $\begin{array}{l}\text { Pre-dose and 2h-post dose on day } 1 \text {, day } 28 \text {, day } 196 \\
\text { and day } 364 .\end{array}$ \\
\hline A2314 & $\begin{array}{l}\text { Phase III, efficacy, } \\
\text { safety }\end{array}$ & $\begin{array}{l}150 \text { and } 450 \mathrm{mg} \text { QD } \\
\text { for } 52 \text { weeks. }\end{array}$ & Asthma patients & $\begin{array}{l}\text { Pre-dose and } 2 \text { h-post dose on day } 1 \text {, day } 28 \text {, day } 196 \\
\text { and day } 364 .\end{array}$ \\
\hline A2125 & $\begin{array}{l}\text { Phase I, bioequiva- } \\
\text { lence }\end{array}$ & $450 \mathrm{mg}$ SD & Healthy subjects & $\begin{array}{l}0 \text { (pre-dose), } 0.25,0.5,1,1.5,2,3,4.5,6,8,12,24,48 \text {, } \\
72 \text { and } 96 \text { h post dose in period } 1 \text { and } 2 .\end{array}$ \\
\hline A2116 & $\begin{array}{l}\text { Phase I, DDI with } \\
\text { cyclosporine }\end{array}$ & $150 \mathrm{mg}$ SD & Healthy subjects & $\begin{array}{l}0 \text { (pre-dose), } 0.25,0.5,1,1.5,2,3,4.5,6,8,12,24,28 \\
36,48,60,72,84 \text { and } 96 \mathrm{~h} \text { post dose in period } 1 \text { and } 2 .\end{array}$ \\
\hline A2120 & $\begin{array}{l}\text { Phase I, DDI with } \\
\text { probenecid }\end{array}$ & $150 \mathrm{mg}$ SD & Healthy subjects & $\begin{array}{l}0 \text { (pre-dose), } 0.25,0.5,1,1.25,1.5,2,3,4.5,6,8,12 \text {, } \\
24,48,72 \text { and } 96 \text { h post dose. }\end{array}$ \\
\hline A1102 & $\begin{array}{l}\text { Phase I, Food effect } \\
\text { in Japanese }\end{array}$ & $450 \mathrm{mg}$ SD & Healthy subjects & $\begin{array}{l}0 \text { (pre-dose), } 0.25,0.5,1,1.5,2,3,4,6,8,12,24,48 \text {, } \\
72 \text { and } 96 \text { h post dose. }\end{array}$ \\
\hline A2107 & $\begin{array}{l}\text { Phase I, Renal } \\
\text { impairment }\end{array}$ & $450 \mathrm{mg}$ SD & $\begin{array}{l}\text { Healthy subjects, patients } \\
\text { with renal impairment }\end{array}$ & $\begin{array}{l}0 \text { (pre-dose), } 0.25,0.5,1,2,3,5,6,8,10,24,30,48, \\
54 \text { and } 68 \text { h post dose. }\end{array}$ \\
\hline A2108 & $\begin{array}{l}\text { Phase I, Hepatic } \\
\text { impairment }\end{array}$ & $450 \mathrm{mg}$ SD & $\begin{array}{l}\text { Healthy subjects, patients } \\
\text { with hepatic impairment }\end{array}$ & $\begin{array}{l}0 \text { (pre-dose), } 0.25,0.5,1,2,3,6,8,12,24,48,72,96 \\
\text { and } 120 \mathrm{~h} \text { post dose. }\end{array}$ \\
\hline A2126 & $\begin{array}{l}\text { Phase I, QT } \\
\text { prolongation }\end{array}$ & $\begin{array}{l}450 \mathrm{mg}, 1800 \mathrm{mg} \text { QD } \\
\text { for } 5 \text { days. }\end{array}$ & Healthy subjects & $\begin{array}{l}0 \text { (pre-dose), } 0.25,0.5,1,2,3,4,5,8,12 \text {, and } 24 \text { h post } \\
\text { dose on day } 1 \text { and day } 5 \text { in period } 1 \text { to } 4 \text {. }\end{array}$ \\
\hline
\end{tabular}

DDI: Drug-drug interaction; QD: once daily; SD: single dose. All Phase I studies were carried out in healthy subjects, except where indicated (A2107 and A2108); all Phase III studies were carried out in asthma patients on medium or high dose inhaled corticosteroids plus 1 or 2 additional controllers.

The effect of covariates (bodyweight, renal function, age, race and sex) on the PK model was investigated after an adequate structural and stochastic model had been identified. In the case of renal function, two alternative models were tested, one with estimated glomerular filtration rate (eGFR) normalized to a body surface area (BSA) of $1.73 \mathrm{~m}^{2}$, and the other with absolute GFR, which was derived from eGFR and individual BSA [19]. The two models were compared and the one with better performance was carried forward.

Continuous covariates were modeled with a power relationship, after normalization using population median values. For example, the effect of bodyweight on clearance was described as:

$$
\mathrm{CL}_{\mathrm{i}}=\mathrm{CL}_{\mathrm{pop}} \cdot\left(\frac{\mathrm{WT}_{\mathrm{i}}}{\mathrm{WT}_{\text {median }}}\right)^{\theta} \cdot e^{\eta_{\mathrm{i}}}
$$

Here, $\mathrm{CL}_{\mathrm{i}}$ is the individual $\mathrm{CL} / \mathrm{F}$ in subject $i, \mathrm{CL}_{\text {pop }}$ is the typical population value of drug clearance, $\mathrm{WT}_{\mathrm{i}}$ is the bodyweight of subject $i, W_{\text {median }}$ is the median value of bodyweight in all subjects, $\theta$ is the covariate relationship of bodyweight and clearance, and $\eta_{i}$ is the BSV in subject $i$ that follows a normal distribution with mean 0 and variance $\omega^{2}$.

Categorical covariates were modeled as a ratio to the population mean. For example, the effect of sex on clearance was modeled as:

$$
\mathrm{CL}_{\mathrm{i}}=\mathrm{CL}_{\text {pop }} \cdot \theta_{\text {sex }} \cdot e^{\eta_{\mathrm{i}}}
$$

Covariate-parameter relationships were tested based on clinical interest, physiological meaning and previous knowledge, supported by diagnostic plots. All the covariates were included in a single full covariate model and jointly estimated $[15,20]$. Statistical significance was determined by whether the corresponding confidence interval estimated by NONMEM included 1 (for categorical covari- ate estimated as ratio) or 0 (for continuous covariates estimated as power), and supplemented by an assessment of its impact on steady-state exposure.

Visual predictive checks (VPCs) and diagnostics based on conditional weighted residuals (CWRES) and normalized prediction distribution errors (NPDE) were used to provide an assessment of the model's ability to describe the data and suitability for simulation. Simulations were conducted to investigate the impact of covariates on steady state exposure. A typical patient was defined as an asthma patient with all covariate values set to their respective median. Exposure was then simulated and compared with the typical patient by varying covariate values, one at a time. Continuous covariates took values at $5^{\text {th }}$ and $95^{\text {th }}$ percentile, while categorical covariates took values of all possible levels.

\section{Results}

\section{Demographics and data distribution}

Demographic information is summarized in > Table 2. In total, 1281 subjects were included in the PK dataset, which consisted of 996 asthma patients and 285 healthy subjects. There were 37 adolescent patients in the dataset ( 12 to $<18$ years), with the remaining subjects being adults.

The distributions of observed $\mathrm{Cmax}$ and $\mathrm{Cmin}$ are shown in - Fig. 1 on the logarithmic scale. There is a clear skewness in the Cmax. The distribution of $\mathrm{Cmin}$ is approximately symmetric (no skewness) with long tails at both ends of the distribution, indicating an over-dispersion.

\section{Population PK model}

Fevipiprant PK was well described by a 2-compartment model with first-order absorption and first-order elimination. Age, weight and 
- Table 2 Demographics

\begin{tabular}{|c|c|c|c|c|c|}
\hline Study & $\mathbf{N}$ & Age (Year) & Weight (kg) & eGFR $\left(\mathrm{mL} / \mathrm{min} / 1.73 \mathrm{~m}^{2}\right)$ & GFR (mL/min) \\
\hline A1102 & 14 & $31.5[20-42]$ & $56.8[46.2-70.4]$ & $120[93.7-162]$ & $114[86.1-137]$ \\
\hline A2107 & 45 & $60[38-74]$ & $81[50.5-103]$ & $74.8[4.19-143]$ & $78.3[4.63-171]$ \\
\hline A2108 & 42 & $59.5[26-68]$ & $80.8[49.1-108]$ & $85.6[60.4-185]$ & $92.9[62.5-220]$ \\
\hline A2116 & 16 & $28[20-52]$ & 78 [64.5-88.7] & 99.9 [78.9-139] & $116[88.8-138]$ \\
\hline A2120 & 16 & $27.5[19-55]$ & $65.2[50.9-87.3]$ & $104[82.1-120]$ & $105[79-138]$ \\
\hline A2125 & 108 & $34.5[19-54]$ & $73.7[60.2-89.5]$ & $97.2[60.3-158]$ & 104 [66.8-159] \\
\hline A2126 & 44 & $30[19-48]$ & $77.6[62-100]$ & 104 [69.9-138] & $118[76.3-161]$ \\
\hline A2307 & 507 & $52[12-85]$ & $74.9[33-188]$ & 85.6 [55-159] & $90.4[48.5-174]$ \\
\hline A2314 & 489 & $52[12-82]$ & $76.6[40-142]$ & $86.4[55.7-152]$ & $91.8[49-171]$ \\
\hline Adolescents $(12-<18)$ & 37 & $14[12-17]$ & $54[33-114]$ & 99.5 [67.7-132] & $88.8[54.1-128]$ \\
\hline Adults $(>=18)$ & 1244 & $50[18-85]$ & $75.4[34-188]$ & $87.8[4.19-185]$ & $93.2[4.63-220]$ \\
\hline Total asthma & 996 & $52[12-85]$ & 75 [33-188] & 86.1 [55-159] & $91.2[48.5-174]$ \\
\hline Total HV * & 285 & $38[19-74]$ & $74.6[46.2-108]$ & $97.2[4.19-185]$ & $105[4.63-220]$ \\
\hline All & 1281 & 50 [12-85] & 75 [33-188] & 88.1 [4.19-185] & 93 [4.63-220] \\
\hline
\end{tabular}

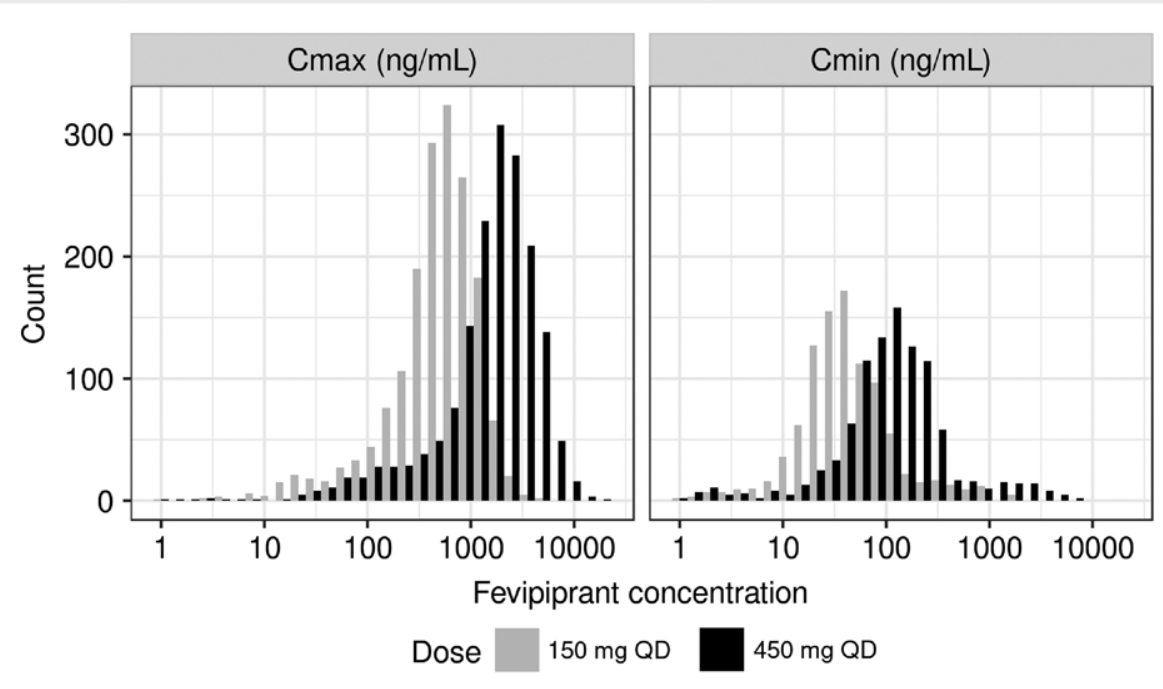

- Fig. 1 Distribution of observed Cmax and Cmin in Phase III studies. Data only included steady-state PK samples from both Phase III studies with time after previous dose being $2 \pm 1 \mathrm{hr}$ for $\mathrm{Cmax}$ and $24 \pm 2 \mathrm{~h}$ for $\mathrm{Cmin}$, respectively.

renal function had a small, statistically significant impact on $\mathrm{CL} / \mathrm{F}$. The model with eGFR and absolute GFR showed similar performance and the one using absolute GFR was carried forward [21, 22].

Data explorations revealed that observed $\mathrm{Cmin}$ in asthma patients from the Phase III studies were consistently higher than those in healthy subjects from Phase I studies (Supplement Fig. S1). To characterize such a systematic difference, a disease effect was added on $\mathrm{CL} / \mathrm{F}, \mathrm{VC} / \mathrm{F}$ and $\mathrm{Q} / \mathrm{F}$, which used asthma patient as reference and estimated the ratio in healthy subjects. The model also included a study effect on CL/F and Ka to account for apparent differences that could not be explained by other covariates. Additionally, a hepatic impairment factor was added on clearance to account for the higher exposure observed in patients with moderate and severe hepatic impairment from the hepatic impairment study.
The model estimated the BSV on CL/F, Vc/F and Q/F. A lognormal distribution was assumed on $\mathrm{Vc} / \mathrm{F}$ and $\mathrm{Q} / \mathrm{F}$. Given the overdispersed and skewed distribution of observed data, BSV on CL/F was modeled using a TGH distribution, which showed better description of the observed data than a lognormal distribution (Supplement Fig. S2 and S3). BSV on Ka, Vp/F and the TGH distribution parameters ( $g$, $h$ and $s$ ) were fixed with a variance of 0.0081 .

A combination of proportional and additive error was used. The additive component of the residual error converges towards 0 . To stabilize the model, it was subsequently fixed to a small value $(1 \times$ $10^{-4}$ ), which is significantly lower than the lower limit of quantification (1 ng/mL) and thus should not have any observable impact on modeling results. 
The parameter estimates for the final model are presented in - Table 3. For a typical 48-year-old asthma patient with GFR of 93 $\mathrm{mL} / \mathrm{min}$ and bodyweight of $75 \mathrm{~kg}$, the total volume of distribution is approximately $558 \mathrm{~L}$. Fevipiprant is cleared from the central com-

- Table 3 Final model parameters

\begin{tabular}{|c|c|c|}
\hline Parameter & Value $(95 \% \mathrm{Cl})$ & $\begin{array}{l}\text { Shrinkage } \\
(\%)\end{array}$ \\
\hline \multicolumn{3}{|l|}{ Structural parameters } \\
\hline $\mathrm{CL} / \mathrm{F}(\mathrm{L} / \mathrm{h})$ & $32.8(31.6-34)$ & \\
\hline $\mathrm{Vc} / \mathrm{F}(\mathrm{L})$ & $110(99.6-121)$ & \\
\hline Ka $(1 / \mathrm{h})$ & $0.572(0.534-0.613)$ & \\
\hline $\mathrm{Q} / \mathrm{F}(\mathrm{L} / \mathrm{h})$ & $8.58(7.48-9.85)$ & \\
\hline $\mathrm{Vp} / \mathrm{F}(\mathrm{L})$ & $448(435-461)$ & \\
\hline \multicolumn{3}{|l|}{ Covariates } \\
\hline $\mathrm{CL} / \mathrm{F}$ : weight (power) & $0.41(0.296-0.525)$ & \\
\hline $\mathrm{CL} / \mathrm{F}:$ age (power) & $-0.108(-0.178-0.0384)$ & \\
\hline CL/F: GFR (power) & $0.218(0.142-0.293)$ & \\
\hline CL/F: disease (ratio) & $1.62(1.52-1.73)$ & \\
\hline CL/F: A1102 (ratio) & $0.857(0.725-1.01)$ & \\
\hline CL/F: A2126 (ratio) & $1.36(1.2-1.53)$ & \\
\hline $\begin{array}{l}\text { CL/F: Hepatic Impairment * } \\
\text { (ratio) }\end{array}$ & $0.487(0.404-0.588)$ & \\
\hline Vc/F: disease (ratio) & $1.3(1.1-1.53)$ & \\
\hline $\begin{array}{l}\text { Vc/F: Hepatic Impairment * } \\
\text { (ratio) }\end{array}$ & $0.445(0.203-0.976)$ & \\
\hline Vc/F: weight (power) & $0.835(0.576-1.09)$ & \\
\hline Ka: A2107 (ratio) & $1.32(1.14-1.52)$ & \\
\hline Q/F: disease (ratio) & $2.79(2.36-3.31)$ & \\
\hline \multicolumn{3}{|l|}{ TGH distribution parameter } \\
\hline$g$ & $-0.046(-0.149-0.0572)$ & \\
\hline$h$ & $0.602(0.539-0.672)$ & \\
\hline$s$ & $0.255(0.235-0.278)$ & \\
\hline \multicolumn{3}{|c|}{ Residual error (Standard deviation) } \\
\hline Proportional & $0.649(0.64-0.659)$ & 8.5 \\
\hline Additive $(\mathrm{ng} / \mathrm{mL})$ & $1 \times 10^{-4}$ Fixed & \\
\hline \multicolumn{3}{|c|}{ Between subject variability (Variance) } \\
\hline BSV: CL/F \# & 0.0081 Fixed & \\
\hline BSV: Vc/F & $0.606(0.517-0.695)$ & 23.6 \\
\hline BSV: Ka & 0.0081 Fixed & \\
\hline BSV: Q/F & $0.369(0.292-0.447)$ & 47.0 \\
\hline BSV: $\mathrm{Vp} / \mathrm{F}$ & 0.0081 Fixed & \\
\hline BSV: $g$ & 0.0081 Fixed & \\
\hline BSV: $h$ & 0.0081 Fixed & \\
\hline BSV: $s$ & 0.0081 Fixed & \\
\hline Z (TGH distribution) & 1 Fixed & \\
\hline \multicolumn{3}{|c|}{$\begin{array}{l}\text { BSV: between subject variability. Cl: confidence interval. CL/F: apparent } \\
\text { clearance. g: skewness parameter in TGH distribution. GFR: glomerular } \\
\text { filtration rate. h: tail-heaviness parameter in TGH distribution. Ka: } \\
\text { absorption rate constant. Q/F: apparent inter-compartment clearance. s: } \\
\text { scale parameter in TGH distribution. TCH: Tukey's g-and-h distribution. } \\
\text { Vc/F: apparent central volume of distribution. Vp/F: apparent peripheral } \\
\text { volume of distribution. Z: standard normal distribution component in } \\
\text { TGH distribution. }{ }^{*} \text { Hepatic Impairment includes patients from A2108 } \\
\text { with moderate and severe hepatic impairments. }{ }^{\#} \text { Added on CL/F for } \\
\text { MU-reference. }\end{array}$} \\
\hline
\end{tabular}

partment with a linear clearance of $32.8 \mathrm{~L} / \mathrm{h}$. The relationship of $\mathrm{CL} / \mathrm{F}$ with its covariates is described by:

$$
\mathrm{CL} / \mathrm{F}=32.8\left(\frac{\mathrm{WT}}{75}\right)^{0.41} \cdot\left(\frac{\mathrm{Age}}{48}\right)^{-0.108} \cdot\left(\frac{\mathrm{GFR}}{93}\right)^{0.218} \cdot 1.62^{\mathrm{HV}} \cdot \theta^{\text {Study }} \cdot \theta^{\mathrm{HI}} \cdot \mathrm{BSV}
$$

where $\theta^{\text {Study }}$ equals to 0.857 for A1102 and 1.36 for study A2126. $\theta^{\mathrm{HI}}$, which represents the ratio of $\mathrm{CL} / \mathrm{F}$ with moderate and severe hepatic impairment from study A2108, was estimated to be 0.487 . The BSV component is described by a TGH distribution:

$$
\mathrm{BSV}=\exp \left(\frac{e^{-0.046 \times Z_{i}}-1}{-0.046} \cdot e^{\left(0.602 \times Z_{i}^{2} / 2\right)} \cdot 0.255\right), \quad Z_{i} \sim N(0,1)
$$

Consistent with observed lower exposure, healthy subjects showed $62 \%$ higher $\mathrm{CL} / \mathrm{F}, 30 \%$ higher $\mathrm{Vc} / \mathrm{F}$ and $179 \%$-fold higher Q/F.

All the structural and random effects have good precision with narrow $95 \% \mathrm{Cl}$.

\section{Model diagnostics and VPC}

The goodness-of-fit was graphically evaluated ( $\triangleright$ Fig. 2). Both the CWRES and NPDE showed an even distribution around the line of zero, when plotted against time and population prediction, indicating a good description of observed data by the final model. There is a deviation from the line of unity in the plot of population prediction vs observation. Given that the VPC showed a proper characterization of the data ( $\vee$ Fig. 3 ), both at the central trend and the extremes, the model is deemed as appropriate to describe the data. VPC for all the Phase I studies showed proper characterization of the central trend, and there was a tendency that the model over-predicted variability in healthy subjects (Supplement Fig. S4).

\section{Simulation}

Simulations were conducted to investigate the impact of age, weight, absolute GFR and disease effect on fevipiprant steady-state exposure. Exposure in healthy subjects was simulated to be $37 \%$ lower than that in asthma patients (Supplementary Table S1 and Fig. S5). Age, weight and absolute GFR only showed limited impact on fevipiprant exposure; by varying the covariate values from $5^{\text {th }}$ to $95^{\text {th }}$ percentile, the difference relative to a typical patient is at most 16\% (Supplementary Table S2-S4 and Fig. S6-S8).

\section{Simulation estimation with the final model}

To investigate the appropriateness of the parameter estimation of the TGH distribution in the final model, 24 datasets were simulated using the final model structure and parameter values, including all the BSV and residual errors. The final model was then used to estimate the parameter values on the simulated datasets.

An illustrative distribution of the simulated profiles is presented in Supplementary Fig. S9. Consistent with observed data, the simulated distribution also showed a skewed $\mathrm{Cmax}$ and an overdispersed Cmin.

Among the 24 simulated datasets, 21 datasets had their models converge successfully. The estimated parameters from simulated datasets were compared to the parameter value and their $95 \% \mathrm{Cl}$ of the final model. The majority of parameters from the simulated datasets lie within the $95 \%$ confidence intervals of their respective parameters from the final model, indicating that the TGH distribu- 

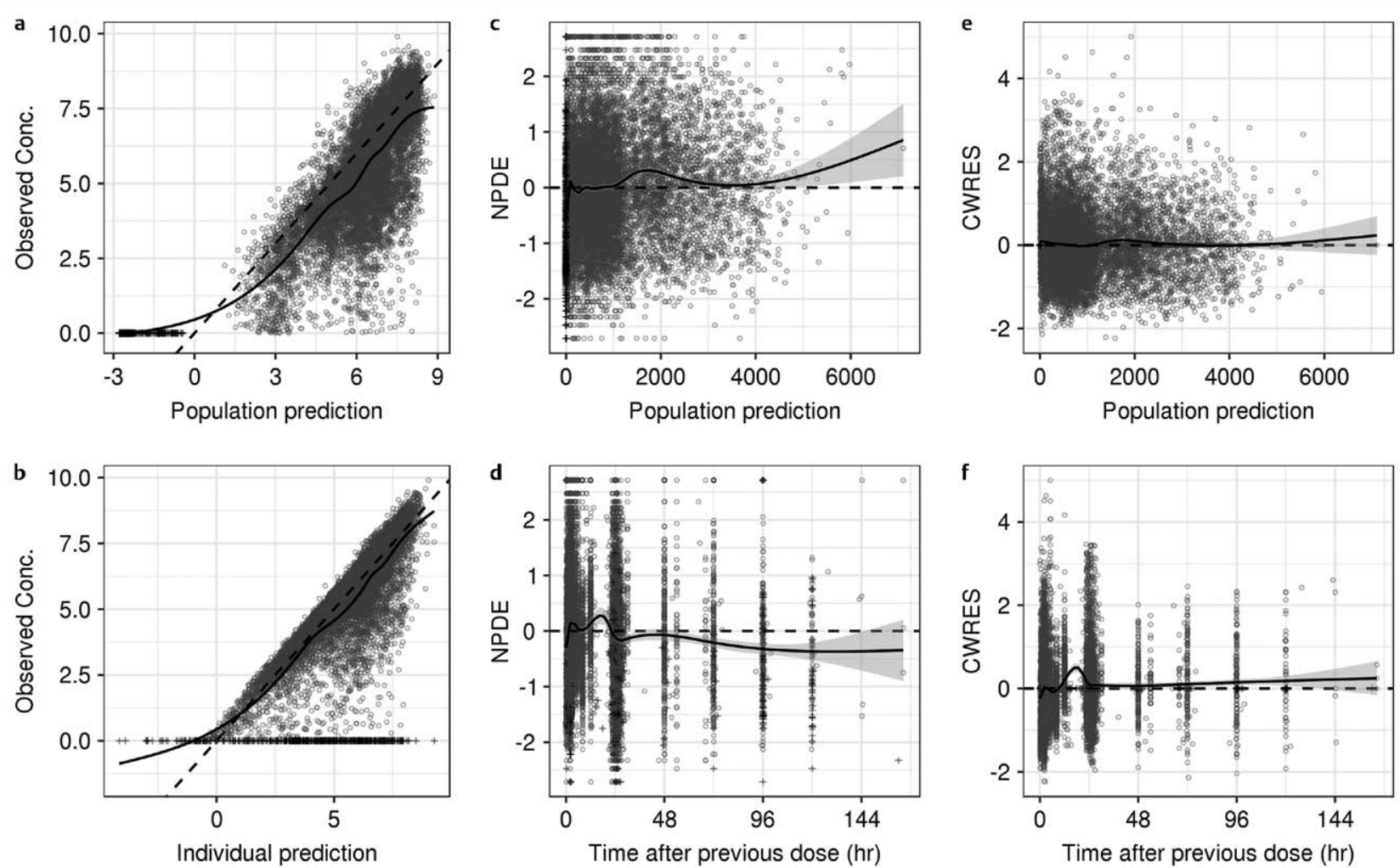

- Fig. 2 Model diagnostics. Plot $\mathbf{a}$ and $\mathbf{b}$ are population prediction (EPRED) and individual prediction vs observed concentration, respectively. Data were log-transformed before plotting. Plot $\mathbf{c}$ and $\mathbf{d}$ are the NPDE (normalized prediction distribution errors) versus population prediction (EPRED) and time after previous dose, respectively. Plot $\mathbf{e}$ and $\mathbf{f}$ are the conditional weighted residuals (CWRES) versus population prediction and time after previous dose, respectively. Crosses are the BLOQ (below the lower limit of quantification) samples. Dashed lines are line of unity $(y=x)$ in plot $\mathbf{a} \& \mathbf{b}$ and line equal to 0 in plot $\mathbf{c}$ to $\mathbf{f}$. Solid lines are the smooth regression line as implemented in ggplot2 package under $R$.

tion as described in this report was adequately estimated by the estimation algorithm ( $\vee$ Fig. 4).

\section{Discussion}

The population PK of fevipiprant in both healthy subjects and asthma patients was well described by a two-compartment mixed effect model. Both the NPDE and VPC showed that the model had an adequate prediction ability.

In particular, for the data in asthma patients from phase III studies, the model described well both the central trend and the variability. For healthy volunteers in the Phase I studies, the VPC showed in general a good prediction of the central trend but over-predicted the variability. This is largely due to the lower variability in phase I studies compared to phase III studies. Considering the good VPC for the asthma patient population and the good residual based diagnostics, the derived final model is deemed adequate to describe the observed data.

We observed a deviation from the line of unity in the plot of population prediction versus observation. Due to the non-normal distribution of the observed data, such an observation should be expected, and points to the fundamental flaws of this type of diagnostic plots as discussed in a previous report [23]. After accounting for the BSV, the individual prediction vs observation showed good agreement with the line of unity and CWRES and NPDE versus predictions did not show any obvious residual trend. Consequently, this deviation should not be of concern in terms of model quality.

The exact reason for the over-dispersion and skewness in observed PK data is unclear; however, this was a major challenge of modeling, since the usual modeling methodology was not designed to accommodate such a distribution. Modeling the data on log scale did not provide any improvement in model performance. Although there are different methods proposed in the past to model the nonGaussian data, the TGH distribution used in the current model is a transformation of standard normal distribution with different parameters for skewness and over-dispersion [13,24]. The observed PK data could be modeled on the original scale without any complex transformation. Together with the scaling factor, it is a flexible alternative to characterize the non-normal data. Diagnostic plots and VPCs showed that it is better than a lognormal distribution, and appropriate to describe the observed data.

The simulation-estimation using the final model showed that NONMEM could successfully estimate the parameters. Even though such an experiment is not a fully-fledged evaluation of the distribution for population PK modeling in general, the successful reestimation of model parameters indicates that at least for the current model the distribution could be properly characterized in NONMEM. The SAEM estimation algorithm implemented in NON- 


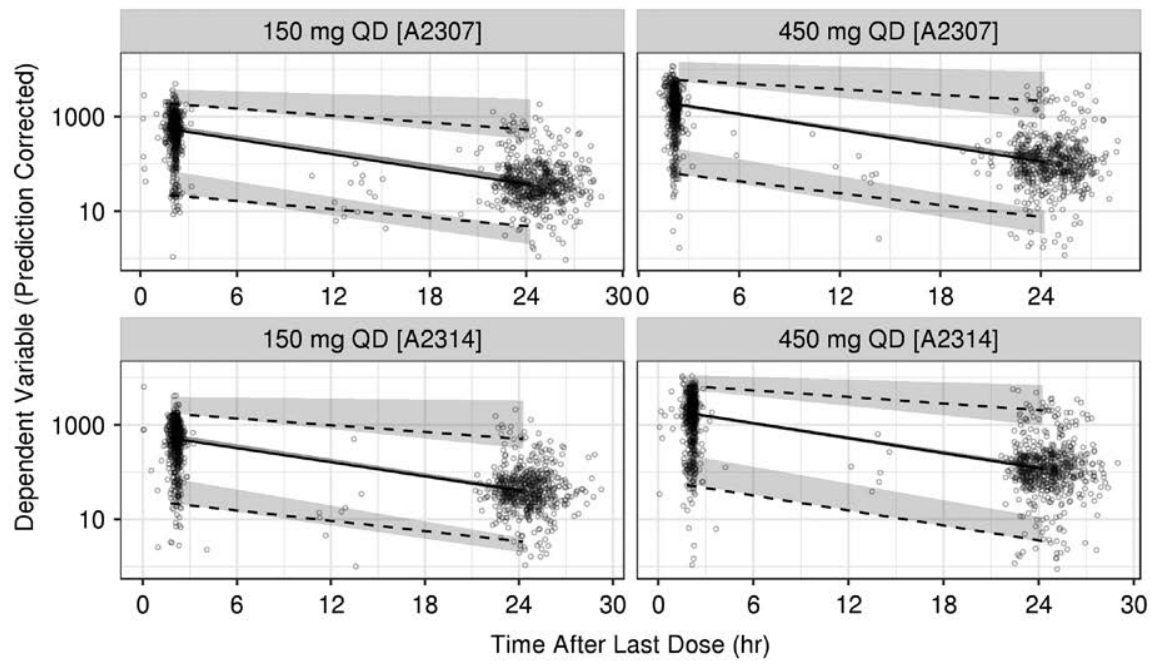

- Fig. 3 VPC plots of phase III studies. QD: once daily dose. VPC: visual predictive check. Black open circles are observed concentrations. Central shaded areas represents the $95 \% \mathrm{Cl}$ (confidence interval) of the simulated median, and peripheral shaded area are the $95 \% \mathrm{Cl}$ of 2.5 th and 97.5 th percentile of the simulated profiles. Solid and dashed lines represent the median, 2.5th and 97.5 th percentile of the observed concentrations.

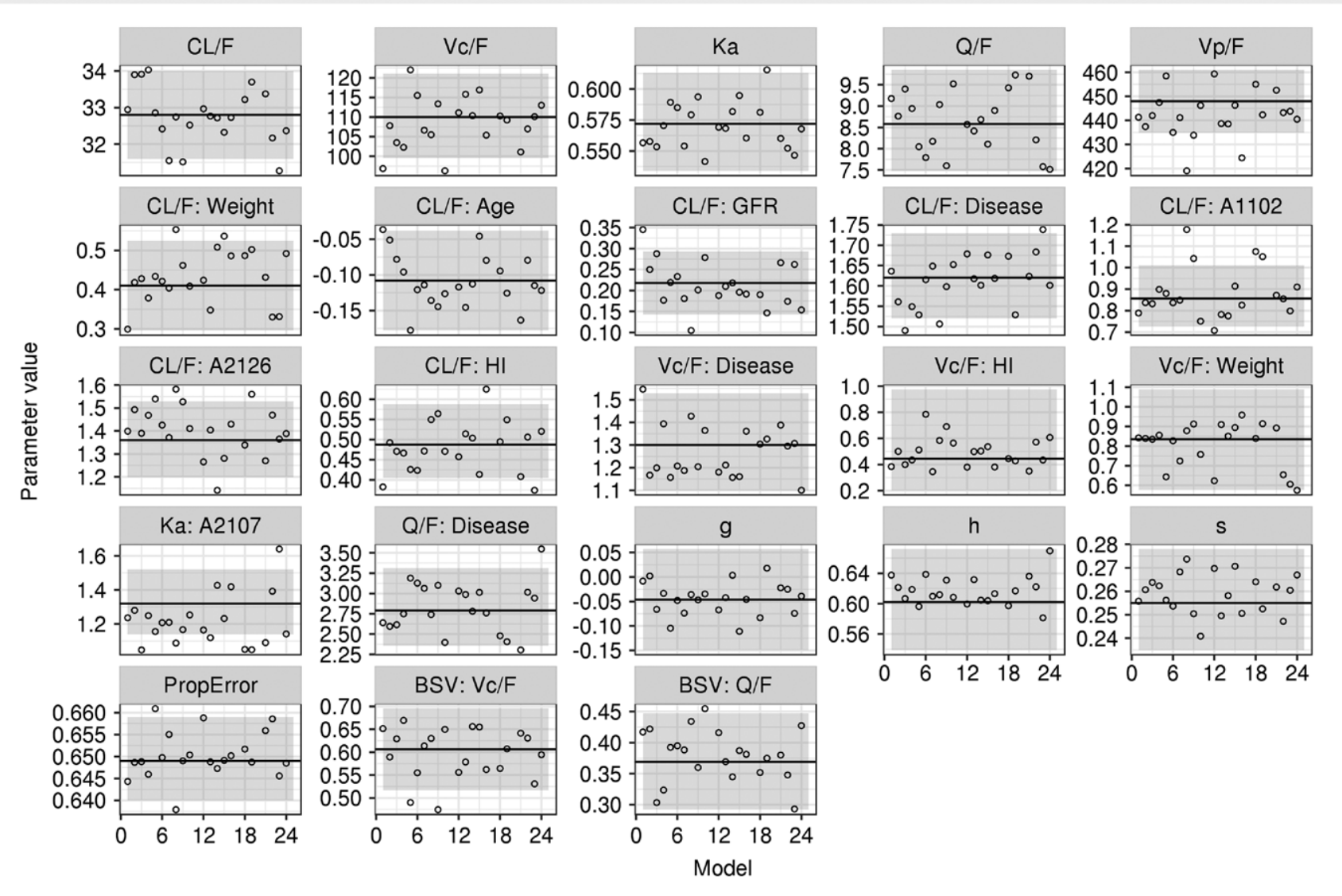

- Fig. 4 Simulation estimation of the final model. HI: hepatic impairment. PropError: proportional residual error. In total, 24 datasets were simulated and re-estimated from the final model, and black open circles are the point estimates of parameter values from each simulated dataset. Central dashed line and shaded area represent the parameter values from the final model used for simulation and their corresponding $95 \%$ confidence intervals. Parameters with fixed values in the model are not included in the plot. 
MEM and used here is especially good at this type of non-normal data, which might be another factor for the successful application of TGH in the model [25].

Overall, the model structure and distribution assumptions are appropriate for the observed data, although there remain some limitations. For example, the QQ-plot of BSV on CL/F with the TGH distribution, even though an improvement compared with lognormal distribution was seen, there was still certain level of deviation from line of unity (Supplement Fig. S2 and Fig. S3). This might be a result of the possibility that parameters other than $\mathrm{CL} / \mathrm{F}$ also follow a non-normal distribution. However, due to model complexity, it was not possible to include further TGH components in the model. Considering the overall good VPC, this limitation is not deemed to interfere with the interpretation and application of the modeling results.

The model confirmed a significant difference between healthy volunteers and asthma patients. Such a difference was also reported for salbutamol, where mild asthmatic patients showed higher exposure than healthy volunteers after oral dosing [26]. One possible explanation for this phenomenon is the increased gastrointestinal permeability leading to the higher exposure in asthma patients [27-29]. Human ADME study estimated that approximately $44 \%$ of fevipiprant was absorbed in healthy volunteers after oral dosing [30]. The fact that $\mathrm{CL} / \mathrm{F}, \mathrm{Vc} / \mathrm{F}$ and $\mathrm{Q} / \mathrm{F}$ are all significantly higher in healthy volunteers might be a further indication of a lower bioavailability in healthy volunteers than that in asthma patients. Nonetheless, it should be noted that disposition of fevipiprant in human involves multiple phase II metabolism enzymes, uptake and efflux transporters [30]. Previous reports showed that asthma disease and the commonly used medications all had the potential to affect drug metabolizing enzymes and transporters [31-33]. Thus, we cannot exclude the possibility that mechanisms other than absorption could also have contributed to the observed difference.

Simulation with the final model showed that steady-state exposure in asthma patients is expected to be $37 \%$ higher than that in healthy volunteers. Due to the relatively small covariate values, all the other statistically significant covariates only produced a limited impact on exposure, which is at most $16 \%$ and not considered clinically relevant.

\section{Conclusions}

Fevipiprant PK was described by a two-compartment model with first-order absorption and first-order elimination. Asthma patients had approximately $37 \%$ higher exposure than that in healthy subjects. Other covariates changed exposure by at most $16 \%$. The TGH distribution was appropriate to describe the over-dispersed and skewed data observed with fevipiprant.

\section{Acknowledgements}

We would like to thank Gholamreza Rahmanzadeh for the bioanalysis of the PK samples, and Kiran Kode for the preparation and validation of modeling dataset.

\section{Conflict of Interest}

All the authors are Novartis employees. The authors report no other conflict of interest in this work.

\section{References}

[1] Wenzel SE. Asthma phenotypes: the evolution from clinical to molecular approaches. Nat Med 2012; 18: 716-725. https://doi. org/10.1038/nm.2678

[2] Brightling CE, Brusselle G, Altman P. The impact of the prostaglandin D2 receptor 2 and its downstream effects on the pathophysiology of asthma. Allergy 2019; 75: 761-768. https://doi.org/10.1111/all.14001

[3] Domingo C, Palomares O, Sandham DA et al. The prostaglandin D2 receptor 2 pathway in asthma: a key player in airway inflammation. Respir Res 2018; 19: 189 https://doi.org/10.1186/s12931-018-0893-x

[4] Santus P, Radovanovic D. Prostaglandin D2 receptor antagonists in early development as potential therapeutic options for asthma. Expert Opin Investig Drugs 2016; 25: 1083-1092. https://doi.org/10.1080/13 543784.2016.1212838

[5] Saunders R, Kaul H, Berair R et al. DP2 antagonism reduces airway smooth muscle mass in asthma by decreasing eosinophilia and myofibroblast recruitment. Sci Transl Med 2019; 11: eaao6451. https://doi. org/10.1126/scitranslmed.aao6451

[6] Sykes DA, Bradley ME, Riddy DM et al. Fevipiprant (QAW039), a Slowly Dissociating CRTh2 Antagonist with the Potential for Improved Clinical Efficacy. Mol Pharmacol 2016; 89: 593-605. https://doi.org/10.1124/ mol.115.101832

[7] White C, Wright A, Brightling C. Fevipiprant in the treatment of asthma. Expert Opin Investig Drugs 2018; 27: 199-207. https://doi.or g/10.1080/13543784.2018.1432592

[8] Gonem S, Berair R, Singapuri A et al. Fevipiprant, a prostaglandin D2 receptor 2 antagonist, in patients with persistent eosinophilic asthma: a single-centre, randomised, double-blind, parallel-group, placebocontrolled trial. Lancet. Respir Med 2016; 4: 699-707. https://doi. org/10.1016/S2213-2600(16)30179-5

[9] Bateman ED, Guerreros AG, Brockhaus F et al. Fevipiprant, an oral prostaglandin DP2 receptor (CRTh2) antagonist, in allergic asthma uncontrolled on low-dose inhaled corticosteroids. Eur Respir J 2017; 50: 1700670. https://doi.org/10.1183/13993003.00670-2017

[10] Brightling CE, Bleecker ER, Erpenbeck V] et al. LUSTER-1 and -2: Two randomized controlled trials of the prostaglandin D2. receptor 2 antagonist, fevipiprant, in asthma. Clin Investig (Lond) 2019; 9: 55-63

[11] Brightling CE, Gaga M, Inoue $\mathrm{H}$ et al. Effectiveness of fevipiprant in reducing exacerbations in patients with severe asthma (LUSTER-1 and LUSTER-2): two phase 3 randomised controlled trials. Lancet. Respir Med. 2020; https://doi.org/10.1016/S2213-2600(20)30412-4

[12] Mould DR, Upton RN. Basic concepts in population modeling, simulation, and model-based drug development-Part 2: Introduction to pharmacokinetic modeling methods. CPT Pharmacometrics Syst Pharmacol 2013; 2: e38. https://doi.org/10.1038/psp.2013.14

[13] Yan Y, Genton MG. The Tukey g-and-h distribution. Significance 2019; 16: 12-13. https://doi.org/10.1111/j.1740-9713.2019.01273.x

[14] Ahn JE, Karlsson MO, Dunne A et al. Likelihood based approaches to handling data below the quantification limit using NONMEM VI. J Pharmacokinet Pharmacodyn 2008; 35: 401-421. https://doi. org/10.1007/s10928-008-9094-4

[15] Bauer RJ. NONMEM Guide: Introduction to NONMEM 7.3.0. Gathersburg. Maryland: ICON plc,; 2015 
[16] Lindbom L, Pihlgren P, Jonsson N. PsN-Toolkit-A collection of computer intensive statistical methods for non-linear mixed effect modeling using NONMEM. Comput Methods Programs Biomed 2005; 79: 241-257. https://doi.org/10.1016/j.cmpb.2005.04.005

[17] Core Team R. R: A Language and Environment for Statistical Computing. 2017;

[18] Bonate PJ. Pharmacokinetic-pharmacodynamic Modeling and Simulation. Second edi. New York: Springer US; 2011

[19] Wang Y, Moss J, Thisted R. Predictors of body surface area. J Clin Anesth 1992; 4: 4-10. https://doi.org/10.1016/0952-8180(92)90111-D

[20] Byon W, Smith MK, Chan P et al. Establishing best practices and guidance in population modeling: An experience with an internal population pharmacokinetic analysis guidance. CPT Pharmacometrics Syst Pharmacol 2013; 2: e51. https://doi.org/10.1038/psp.2013.26

[21] Åsberg A, Bjerre A, Almaas R et al. Measured GFR by utilizing population pharmacokinetic methods to determine iohexol clearance. Kidney Int Reports 2020; 5: 189-198. https://doi.org/10.1016/j. ekir.2019.11.012

[22] European Medicines Agency. Guideline on the evaluation of the pharmacokinetics of medicinal products in patients with decreased renal function 2015

[23] Karlsson MO, Savic RM. Diagnosing model diagnostics. Clin Pharmacol Ther 2007; 82: 17-20. https://doi.org/10.1038/sj.clpt.6100241

[24] Xu G, Genton MG. Tukey g-and-h random fields. J Am Stat Assoc 2017; 112: 1236-1249. https://doi.org/10.1080/01621459.2016.1205501

[25] Bauer RJ. NONMEM tutorial Part II: Estimation methods and advanced examples. CPT Pharmacometrics Syst Pharmacol 2019; 8: 538-556. https://doi.org/10.1002/psp4.12422
[26] Sjöswärd KN, Josefsson M, Ahlner ] et al. Metabolism of salbutamol differs between asthmatic patients and healthy volunteers. Pharmacol Toxicol 2003; 92: 27-32. https://doi. org/10.1034/j.1600-0773.2003.920105.x

[27] Di L, Kerns EH. Transporters. In: Di L, Kerns E Eds. Drug-Like Properties Concepts, Structure Design and Methods from ADME to Toxicity Optimization. Boston: Academic Press; 2016: 113-140

[28] Benard A, Desreumeaux P, Huglo D et al. Increased intestinal permeability in bronchial asthma. J Allergy Clin Immunol 1996; 97: 1173-1178. https://doi.org/10.1016/S0091-6749(96)70181-1

[29] Hijazi Z, Molla AM, Al-Habashi H et al. Intestinal permeability is increased in bronchial asthma. Arch Dis Child 2004; 89: 227 LP-229. https://doi.org/10.1136/adc.2003.027680

[30] Pearson D, Weiss HM, Jin Y et al. Absorption, distribution, metabolism, and excretion of the oral prostaglandin D2 receptor 2 antagonist fevipiprant (QAW039) in healthy volunteers and in vitro. Drug Metab Dispos 2017; 45: 817-825. https://doi.org/10.1124/dmd.117.075358

[31] Aguiar JA, Tamminga A, Lobb B et al. The impact of cigarette smoke exposure, COPD, or asthma status on $A B C$ transporter gene expression in human airway epithelial cells. Sci Rep 2019; 9: 153. https://doi. org/10.1038/s41598-018-36248-9

[32] Upton RA. Pharmacokinetic interactions between theophylline and other medication (Part I). Clin Pharmacokinet 1991; 20: 66-80. https://doi.org/10.2165/00003088-199120010-00005

[33] Anglicheau D, Flamant M, Schlageter MH et al. Pharmacokinetic interaction between corticosteroids and tacrolimus after renal transplantation. Nephrol Dial Transplant 2003; 18: 2409-2414. https://doi.org/10.1093/ndt/gfg381 